Braz J Med Biol Res, November 2011, Volume 44(11) 1156-1163

doi: 10.1590/S0100-879X2011007500136

\section{Protective effects of organoselenium compounds against} methylmercury-induced oxidative stress in mouse brain mitochondrial-enriched fractions

D.F. Meinerz, M.T. de Paula, B. Comparsi, M.U. Silva, A.E. Schmitz, H.C. Braga, P.S. Taube, A.L.

Braga, J.B.T. Rocha, A.L. Dafre, M. Farina, J.L. Franco and T. Posser

The Brazilian Journal of Medical and Biological Research is partially financed by

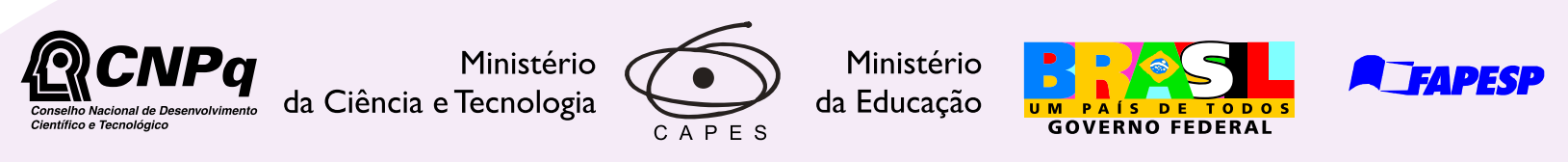

Institutional Sponsors
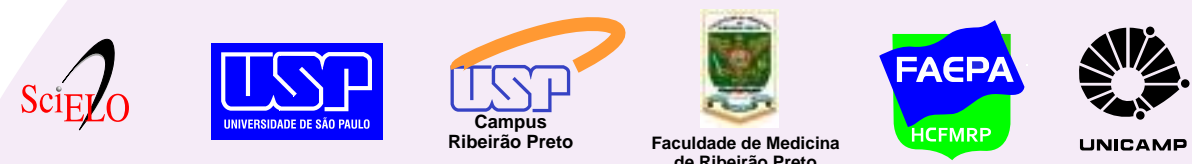

UNICAMP

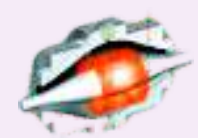

Explore High - Performance MS Orbitrap Technology In Proteomics \& Metabolomics

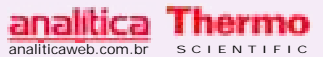




\title{
Protective effects of organoselenium compounds against methylmercury-induced oxidative stress in mouse brain mitochondrial-enriched fractions
}

\author{
D.F. Meinerz², M.T. de Paula², B. Comparsi², M.U. Silva ${ }^{3}$, A.E. Schmitz ${ }^{3}$, \\ H.C. Braga $^{3}$, P.S. Taube ${ }^{2}$, A.L. Braga ${ }^{2}$, J.B.T. Rocha ${ }^{2}$, \\ A.L. Dafre ${ }^{3}$, M. Farina ${ }^{3}$, J.L. Franco ${ }^{1,2}$ and T. Posser ${ }^{1,2}$ \\ ${ }^{1}$ Campus São Gabriel, Universidade Federal do Pampa, São Gabriel, RS, Brasil \\ ${ }^{2}$ Centro de Ciências Naturais e Exatas, Universidade Federal de Santa Maria, Santa Maria, RS, Brasil \\ ${ }^{3}$ Centro de Ciências Biológicas, Universidade Federal de Santa Catarina, Florianópolis, SC, Brasil
}

\begin{abstract}
We evaluated the potential neuroprotective effect of 1-100 $\mu \mathrm{M}$ of four organoselenium compounds: diphenyl diselenide, 3'3-ditrifluoromethyldiphenyl diselenide, $p$-methoxy-diphenyl diselenide, and $p$-chloro-diphenyl diselenide, against methylmercury-induced mitochondrial dysfunction and oxidative stress in mitochondrial-enriched fractions from adult Swiss mouse brain. Methylmercury $(10-100 \mu \mathrm{M})$ significantly decreased mitochondrial activity, assessed by MTT reduction assay, in a dose-dependent manner, which occurred in parallel with increased glutathione oxidation, hydroperoxide formation (xylenol orange assay) and lipid peroxidation end-products (thiobarbituric acid reactive substances, TBARS). The co-incubation with diphenyl diselenide (100 $\mu \mathrm{M}$ ) completely prevented the disruption of mitochondrial activity as well as the increase in TBARS levels caused by methylmercury. The compound 3'3-ditrifluoromethyldiphenyl diselenide provided a partial but significant protection against methylmercuryinduced mitochondrial dysfunction (45.4 $\pm 5.8 \%$ inhibition of the methylmercury effect). Diphenyl diselenide showed a higher thiol peroxidase activity compared to the other three compounds. Catalase blocked methylmercury-induced TBARS, pointing to hydrogen peroxide as a vector during methylmercury toxicity in this model. This result also suggests that thiol peroxidase activity of organoselenium compounds accounts for their protective actions against methylmercury-induced oxidative stress. Our results show that diphenyl diselenide and potentially other organoselenium compounds may represent important molecules in the search for an improved therapy against the deleterious effects of methylmercury as well as other mercury compounds.
\end{abstract}

Key words: Methylmercury; Mitochondria; Oxidative stress; Organoselenium compounds; Diphenyl diselenide

\section{Introduction}

Reactive oxygen/nitrogen species (ROS/RNS) such as superoxide anion, hydrogen peroxide and nitric oxide induce damage to key biological components and cell membranes. In order to counteract the deleterious effects of reactive species, cells developed a specialized machinery of antioxidant defense. Cellular defense against ROS involves enzymes such as catalase, superoxide dismutase and glutathione peroxidase, which play a central role in the detoxification of reactive species $(1,2)$.

Seleno-organic compounds such as ebselen and diphenyl diselenide (DD) $(3,4)$ have a catalytic activity similar to that of the enzyme glutathione peroxidase involving the reduction of peroxides at the expense of thiol compounds $(2,5)$ and represent important molecules whose protective and antioxidant properties against experimental oxidative stress conditions have been reported (6-8). These studies stimulated the search for new organoselenium compounds with catalytic properties similar to those of ebselen and DD, which could provide antioxidant and protective effects in biological systems.

Methylmercury (MeHg) has been recognized as a ubiquitous environmental toxicant whose toxicity is associated with neurological and developmental deficits in animals and humans (9). Nowadays, especially in the Amazon Region,

Correspondence: T. Posser and/or J.L. Franco, Campus São Gabriel, Universidade Federal do Pampa, 97300-000 São Gabriel, RS, Brasil and/or Centro de Ciências Naturais e Exatas, Universidade Federal de Santa Maria, 97105-900 Santa Maria, RS, Brasil. E-mail: thaisposser@unipampa.edu.br and/or jefersonfranco@unipampa.edu.br

Received January 13, 2011. Accepted September 21, 2011. Available online October 14, 2011. Published November $14,2011$. 
gold mining activity has been associated with intense environmental and human contamination with mercury compounds $(10,11)$. Among the mechanisms involved in MeHg neurotoxicity, oxidative stress $(12,13)$ appears to play a central role. MeHg-induced oxidative stress seems to be related to the direct oxidative properties of $\mathrm{MeHg}$ toward endogenous thiols (14) and to its inhibitory effects toward antioxidant enzymes like glutathione peroxidase $(6,15,16)$. Mitochondria appear to be important cellular organelles targeted by MeHg (17), which is known to accumulate in mitochondria, where it can change mitochondrial membrane permeability and cause disruption of mitochondrial membrane potential $(18,19)$. Considerable efforts have been made in the search for new drugs that counteract mercury toxicity. However, until now, no effective treatments are available to completely abolish the toxic effects of $\mathrm{MeHg}(20)$.

In previous studies, the organoselenium compounds DD and ebselen demonstrated potential protective effects against MeHg toxicity $(6,21)$. Moreover, in in vivo studies, DD demonstrated lower toxicity than ebselen (5) and DD reversed $\mathrm{MeHg}$-induced oxidative stress in vivo and in cortical slices $(22,23)$. These data support the potential use of organoselenium compounds against MeHg poisoning.

The aim of the present study was to investigate the potential protective effects of DD and three novel selenium compounds: 3'3-ditrifluoromethyldiphenyl diselenide (DFD), p-methoxy-diphenyl diselenide (MD) and p-chloro-diphenyl diselenide (CLD) against $\mathrm{MeHg}$-induced mitochondrial dysfunction.

\section{Material and Methods}

\section{Chemicals}

Glutathione reductase (G3664), reduced glutathione (GSH), oxidized glutathione (GSSG), $t$-butyl-hydroperoxide (t-bOOH), 5,5'-dithiobis(2-nitrobenzoic acid (DTNB), methylmercury (II) chloride, xylenol orange salt, and methylthiazolyldiphenyl-tetrazolium bromide (MTT) were purchased from Sigma-Aldrich (USA). All other chemicals used in this study were of the highest analytical grade available.

\section{Synthesis and preparation of organoselenium compounds}

All organoselenium compounds (Figure 1) tested in the present study were prepared as previously described (4). Analysis of the hydrogen-1 nuclear magnetic resonance $\left({ }^{1} \mathrm{H}\right.$ NMR) and carbon-13 NMR $\left({ }^{13} \mathrm{C}\right.$ NMR $)$ spectra showed that all compounds presented analytical and spectroscopic data in full agreement with their assigned structures (data not shown). The diselenides were purified by flash chromatography on silica gel (hexane) and identified by $\left({ }^{1} \mathrm{H}\right.$ NMR), ${ }^{13} \mathrm{C}$ NMR and gas chromatography-mass spectrometry (GCMS), which revealed homogeneous product (data not shown). Compounds were dissolved in ethanol immediately prior to use in each assay. The final ethanol in each experiment was $0.1 \%$, and did not affect any of the parameters analyzed when compared to a control sample without ethanol (data not shown). We also investigated the basal activity of the compounds tested for the parameters analyzed in this study. We did not find significant changes when comparing the effects of compounds alone in all experiments performed (data not shown).

\section{Preparation of mouse brain mitochondrial-enriched fractions}

All procedures involving animals were performed according to the Animal Care Guidelines from the National Institutes of Health of the United States of America, and all procedures were approved by the Universidade Federal de Santa Catarina Ethics Committee for animal use (313/ CEUA; 23080.026023/2004-39/UFSC). Mouse brain mito-
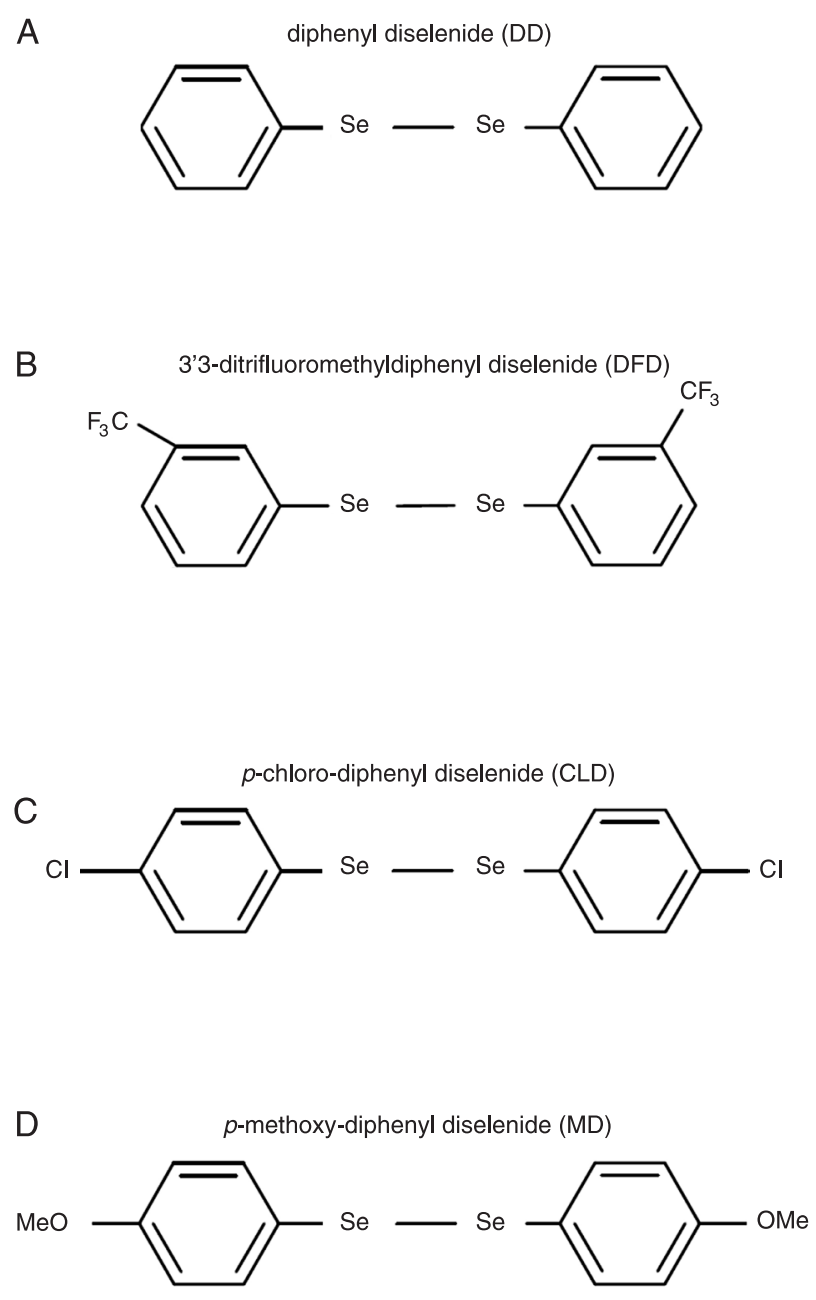

Figure 1. Structures of the organoselenium compounds tested in the present study. 
chondrial-enriched fractions were prepared as described previously (24). Briefly, adult (8-10 weeks) male Swiss mice were sacrificed by decapitation. The whole brain (minus the cerebellum) was removed and homogenized on ice in 10 volumes of isolation medium (10 mM HEPES buffer, $\mathrm{pH}$ 7.0 , containing $220 \mathrm{mM}$ mannitol, $68 \mathrm{mM}$ sucrose, $10 \mathrm{mM}$ $\mathrm{KCl}$, and $0.1 \%$ serum albumin) and the homogenate was centrifuged at $4^{\circ} \mathrm{C}$ for $10 \mathrm{~min}$ at $1000 \mathrm{~g}$. The supernatant was then centrifuged at $17,500 \mathrm{~g}$ for $10 \mathrm{~min}$ at $4^{\circ} \mathrm{C}$, providing a myelin-rich supernatant and a pellet (P2) consisting of synaptosomes and free (extra-synaptosomal) mitochondria. The supernatant was discarded, and the pellet was suspended in the isolation medium without albumin. The samples were kept on ice until the experiments were performed, usually within 10-15 min.

\section{Incubations}

P2 (2 mg protein) was incubated with different concentrations of $\mathrm{MeHg}(0,10,30$, and $100 \mu \mathrm{M})$ diluted in incubation buffer, and/or selenium compounds (1,10, 30, and $100 \mu \mathrm{M})$ in a incubation medium containing $10 \mathrm{mM}$ HEPES buffer, $\mathrm{pH}$ 7.0, $220 \mathrm{mM}$ mannitol, $68 \mathrm{mM}$ sucrose, and $10 \mathrm{mM} \mathrm{KCl}$ (total incubation volume $=300 \mu \mathrm{L}$ ). In previous studies, we found a concentration of about $10 \mu \mathrm{M} \mathrm{Hg}$ in the brain of mice treated orally with $40 \mathrm{mg} / \mathrm{L} \mathrm{MeHg}$ in drinking water (24). Considering the high amount of protein (2 mg), in the present study we used concentrations of $\mathrm{MeHg}$ up to $100 \mu \mathrm{M}$ in order to obtain clear detection of all parameters tested during the in vitro assays. Incubations were carried out at $25^{\circ} \mathrm{C}$. After incubation, mitochondrial dehydrogenase activity, GSH content, total hydroperoxides, and lipid peroxidation (TBARS) were determined. Parallel experiments with the presence of catalase (200 U) were also carried out in order to test the role of hydrogen peroxide $\left(\mathrm{H}_{2} \mathrm{O}_{2}\right)$ in the mechanisms of toxicity and protection of $\mathrm{MeHg}$ and organoselenium compounds, respectively.

\section{Assessment of mitochondrial activity}

Mitochondrial activity was assessed by the conversion of the MTT dye to formazan (17). This assay is based on the ability of mitochondrial enzymes to metabolize MTT into formazan, a reaction that takes place only in functionally intact mitochondria. Briefly, samples $(300 \mu \mathrm{L})$ were incubated for $30 \mathrm{~min}$ at $25^{\circ} \mathrm{C}$. The purple formazan crystals were pelleted by centrifugation, and the supernatant was discarded. The pellets were dissolved in DMSO and the formazan was quantified spectrophotometrically by absorbance measurements at $550 \mathrm{~nm}$. Data are reported as percentage of control. Selenium compounds alone did not interfere with the MTT method described here (data not shown).

\section{Assessment of glutathione and hydroperoxide content and lipid peroxidation}

Glutathione content was measured as nonprotein thiols according to a method previously described (25). After treatment with different concentrations $(10,30$, and $100 \mu \mathrm{M})$ of $\mathrm{MeHg}$ for $30 \mathrm{~min}, 300 \mu \mathrm{L} \mathrm{10 \%}$ trichloroacetic acid was added to the samples $(300 \mu \mathrm{L})$. After centrifugation (4000 $g$ at $4{ }^{\circ} \mathrm{C}$ for $10 \mathrm{~min}$ ), the protein pellet was discarded and free thiol groups were determined in the clear supernatant (which was neutralized with $0.1 \mathrm{M} \mathrm{NaOH}$ ) by the method of Ellman (25). The total hydroperoxide content was assessed using the xylenol orange method (24) that allows the detection of hydrogen peroxide as well as lipid hydroperoxides. Briefly, samples were incubated in the medium described above for $60 \mathrm{~min}$ at $25 \pm 1^{\circ} \mathrm{C}$ in the presence or absence of $\mathrm{MeHg}$ and/or selenium compounds. Then, the xylenol orange reagent, containing $0.25 \mathrm{mM} \mathrm{Fe}\left(\mathrm{NH}_{4}\right)_{2}\left(\mathrm{SO}_{4}\right)_{2}$, $0.25 \mathrm{mM}$ xylenol orange, and $110 \mathrm{mM}$ perchloric acid, was added to the incubation medium. After $30 \mathrm{~min}$, absorbance was recorded at $560 \mathrm{~nm}$ and compared to a hydrogen/ cumene peroxide standard curve. Selenium compounds alone did not interfere with the method described here (data not shown).

The lipid peroxidation end-products were determined by the TBARS assay originally described by Ohkawa et al. (26). After $60 \mathrm{~min}$ of incubation as described for the xylenol orange method, samples were incubated with 0.45 $\mathrm{M}$ acetic acid/ $\mathrm{HCl}$ buffer, $\mathrm{pH} 3.4,0.28 \%$ thiobarbituric acid, $1.2 \% \mathrm{SDS}$, and thereafter at $95^{\circ} \mathrm{C}$ for $60 \mathrm{~min}$ to promote color reaction, measured at $532 \mathrm{~nm}$. Malondialdehyde $(0$ to $3 \mathrm{nmol} / \mathrm{mL}$ ) was used as a standard. Protein concentration was determined by the method of Bradford (27) using bovine serum albumin as standard.

\section{Assessment of glutathione peroxidase (GPx)-like activity of organodiselenides}

The GPx-like activity of the organoselenium compounds was determined using the coupled assay described by Wendel (28), which indirectly monitors the consumption of NADPH at $340 \mathrm{~nm}$. The GPx/GPx-like compounds use GSH to reduce tert-butylhydroperoxide, producing GSSG, which is readily reduced to $\mathrm{GSH}$ by excess glutathione reductase (GR), thus consuming NADPH.

\section{Statistical analysis}

Statistically significant differences among groups were analyzed by one-way ANOVA followed by the Duncan multiple range test when appropriate. Differences were considered to be statistically significant when $\mathrm{P}<0.05$.

\section{Results}

\section{MeHg induces oxidative stress and reduction of mitochondrial metabolic activity}

The toxicity of $\mathrm{MeHg}$ has been demonstrated in in vitro and in vivo models and is generally associated with increased oxidative stress, disruption of oxidative defenses by inhibition of antioxidant enzymes as well as reduction 
of GSH levels in the cell $(15,16)$. Moreover, mitochondria are an important cellular target for $\mathrm{MeHg}$ toxicity (17). In the present study, as shown in Figure 2A, using the MTT reduction test, $\mathrm{MeHg}$ decreased the mitochondrial activity in a concentration-dependent manner. This effect was significantly different from control at concentrations as low as $10 \mu \mathrm{M}$ and a reduction of about $50 \%$ in cell viability was verified at the highest concentration $(100 \mu \mathrm{M})$. This effect was followed by a concentration-dependent decrease in mitochondrial GSH levels (Figure 2B). In parallel, a significant increase in total-hydroperoxide production (Figure 2C) and increased lipid peroxidation were observed with $100 \mu \mathrm{M} \mathrm{MeHg}$ (Figure 2D). The following experiments were performed using $100 \mu \mathrm{M} \mathrm{MeHg}$, which affected all parameters analyzed.

\section{Protective effects of organoselenium compounds against MeHg-induced mitochondrial oxidative stress}

We investigated the potential protective effects of organoselenium compounds against the decrease in mitochondrial activity promoted by $\mathrm{MeHg}$, using the MTT reduction assay. As observed in Figure 3A, DD at concentrations of 30 and $100 \mu \mathrm{M}$ was able to partially and totally
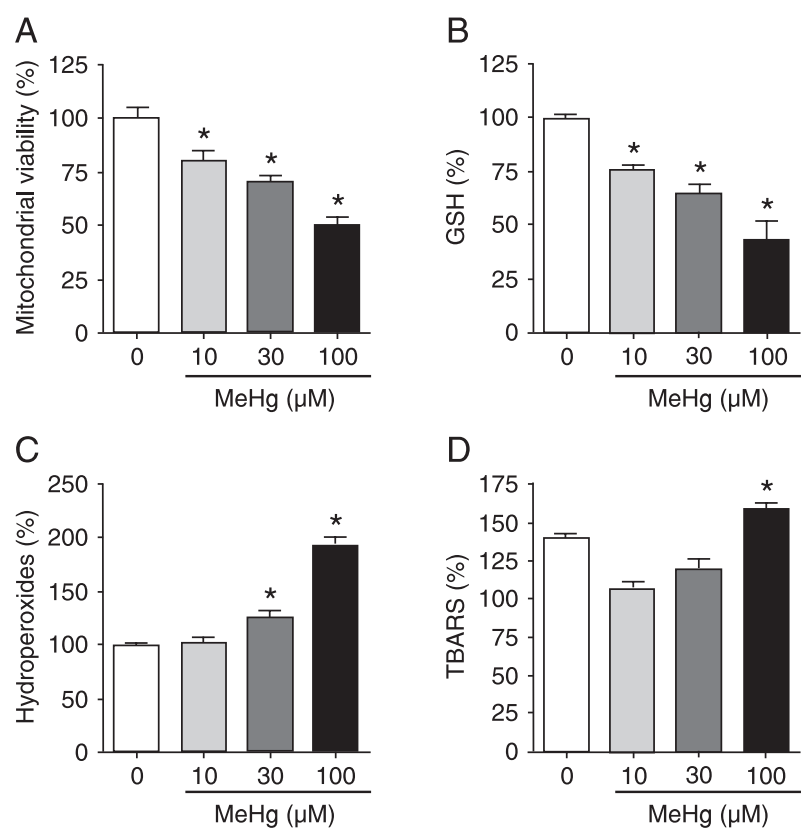

Figure 2. Effects of MeHg on brain mitochondria. Mouse brain mitochondrial-enriched fractions were isolated and incubated with different concentrations $(0,10,30$, and $100 \mu \mathrm{M})$ of $\mathrm{MeHg}$ for $30 \mathrm{~min}$ (MTT test and GSH measurement) or $60 \mathrm{~min}$ (totalhydroperoxide and TBARS content). Data are reported as means \pm SD of percent of control for 4-6 separate assays carried out in duplicate. ${ }^{*} \mathrm{P}<0.05$ compared to control (without MeHg; ANOVA and Duncan post hoc test). $A$, Mitochondrial activity; $B$, GSH levels; $C$, total-hydroperoxides content; $D$, production of thiobarbituric acid reactive substances (TBARS). reverse the effect of $100 \mu \mathrm{M} \mathrm{MeHg}$ on mitochondrial activity, respectively. Only the highest concentration of DFD (100 $\mu \mathrm{M})$ caused a slight reversal of the $\mathrm{MeHg}$-induced reduction of mitochondrial activity (Figure 3B), while CLD and MD did not prevent the effects of $\mathrm{MeHg}$ on mitochondrial function (Figure 3C and D).

Considering the significant decrease in GSH levels promoted by $\mathrm{MeHg}$ treatment, we investigated whether co-incubation of $\mathrm{MeHg}$ in the presence of organoselenium compounds would be able to modulate the decrease in GSH levels caused by this metal. As observed in Figure 4 (A-D), none of the compounds tested was able to protect against the depletion of GSH levels caused by $\mathrm{MeHg}$. In fact, when MD and MeHg were co-administered (Figure 4D), the decrease of GSH levels was greater than in the presence of $\mathrm{MeHg}$ alone, although this effect was not statistically significant $(P=0.08)$.

The antioxidant potential of the different organoselenium compounds against lipid peroxidation induced by $\mathrm{MeHg}$ was investigated by determining TBARS levels. As observed in Figure $5 A$, DD totally blocked the increase in lipid peroxidation induced by $\mathrm{MeHg}$ at a concentration as low as 10
A

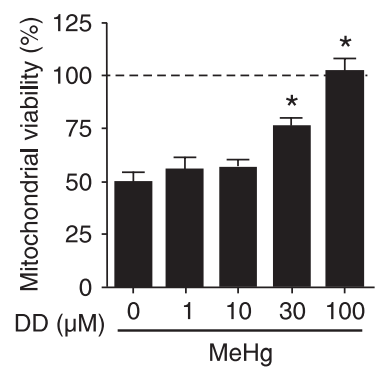

C

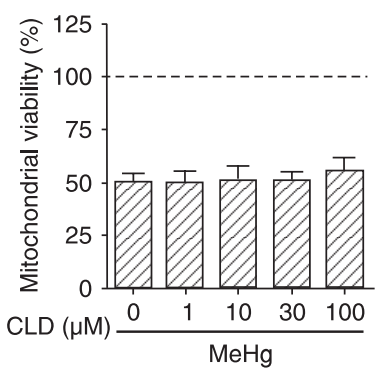

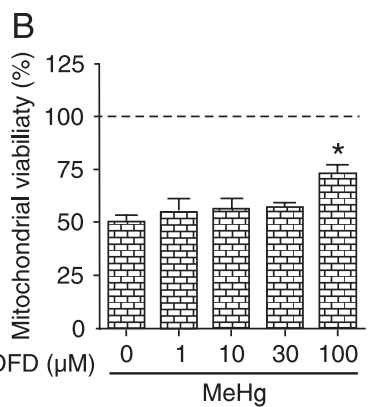

D

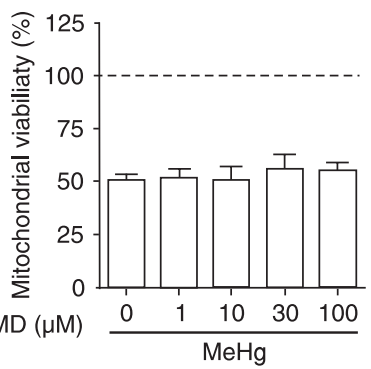

Figure 3. Effects of organoselenium compounds on $\mathrm{MeHg}$ induced decrease in mitochondrial activity. Mouse brain mitochondrial-enriched fractions were incubated with $100 \mu \mathrm{M} \mathrm{MeHg}$ in the presence or absence of different concentrations (1-100 $\mu \mathrm{M})$ of diphenyl diselenide (DD; $A$ ); 3'3-ditrifluoromethyldiphenyl diselenide (DFD; $B$ ); $p$-chloro-diphenyl diselenide (CLD; $C$ ), and $p$-methoxy-diphenyl diselenide (MD; $D$ ). Data are reported as means \pm SD of percent of control for 4-6 separate assays carried out in duplicate. ${ }^{*} \mathrm{P}<0.05$ compared to $\mathrm{MeHg}$ alone (ANOVA and Duncan post hoc test). The dashed line indicates the control without $\mathrm{MeHg}(100 \%)$. 
A

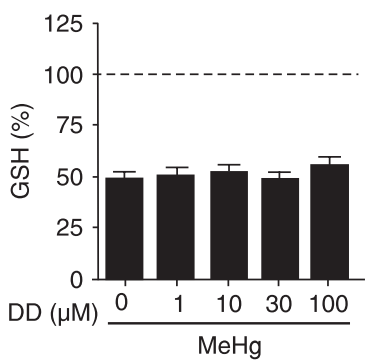

C

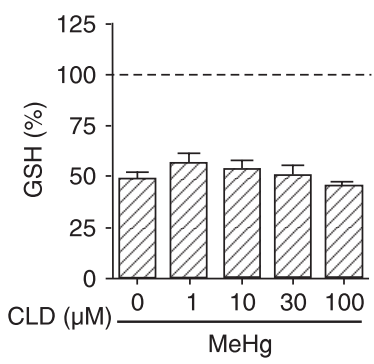

B

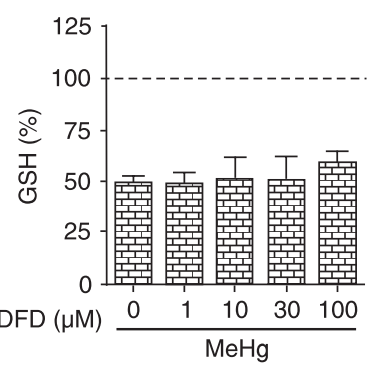

D

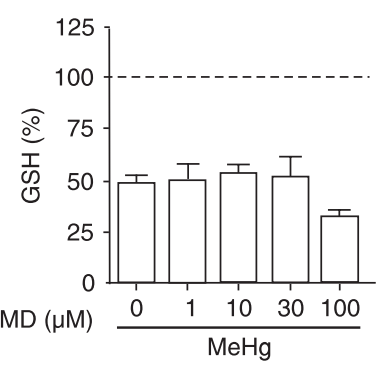

Figure 4. Effects of organoselenium compounds on MeHginduced decrease in reduced glutathione (GSH) levels. Mouse brain mitochondrial-enriched fractions were incubated with 100 $\mu \mathrm{M} \mathrm{MeHg}$ in the presence or absence of different concentrations (1-100 $\mu \mathrm{M}$ ) of diphenyl diselenide (DD; $A$ ); 3'3-ditrifluoromethyldiphenyl diselenide (DFD; $B$ ); $p$-chloro-diphenyl diselenide $(\mathrm{CLD} ; C)$, and $p$-methoxy-diphenyl diselenide (MD; $D$ ). Data are reported as means \pm SD of percent of control for 4-6 separate assays carried out in duplicate. The dashed line indicates the control without $\mathrm{MeHg}(100 \%)$.
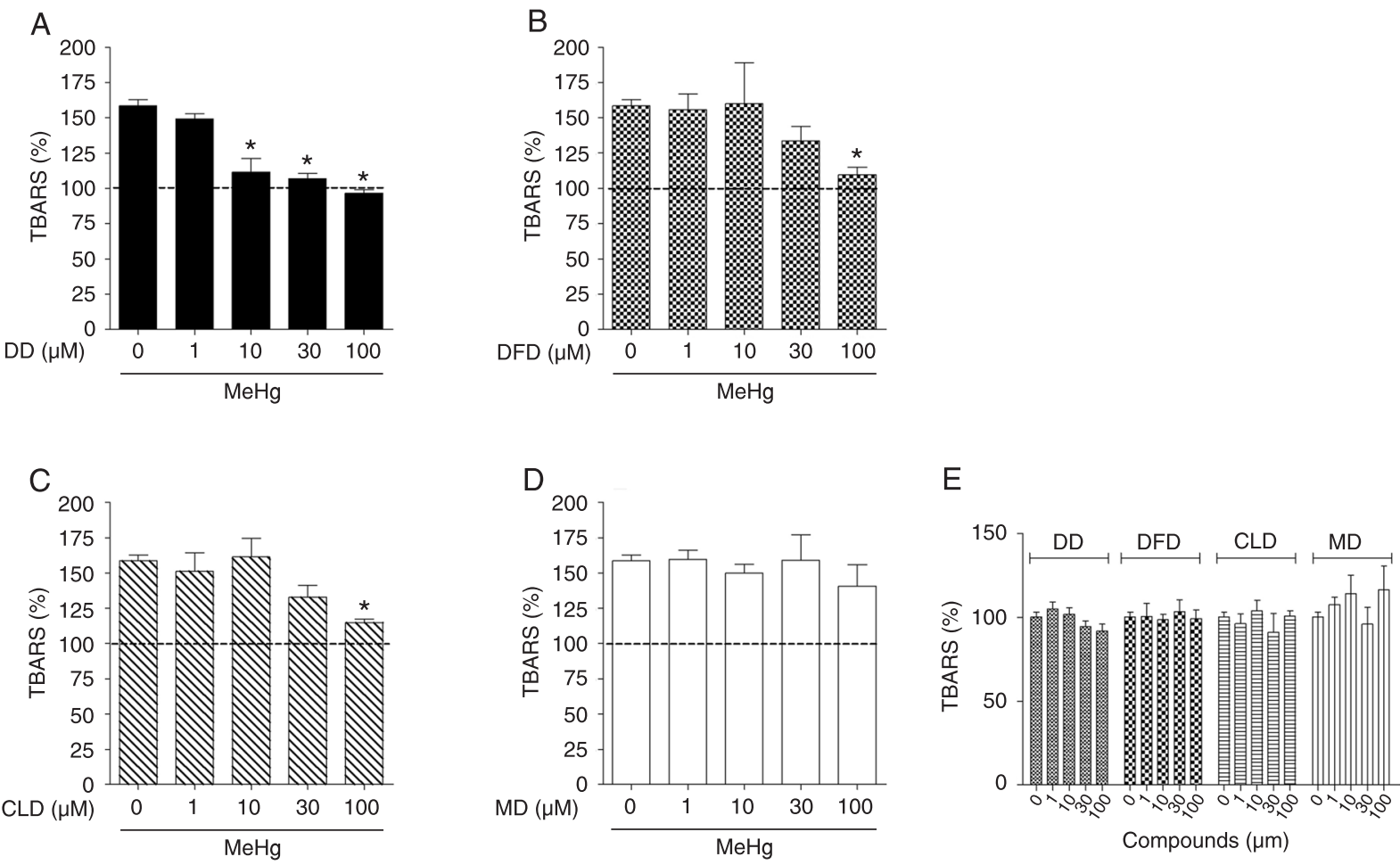

Figure 5. Effects of organoselenium compounds on MeHg-induced increase in the content of thiobarbituric acid reactive species (TBARS) levels. Mouse brain mitochondrial-enriched fractions were incubated with $100 \mu \mathrm{M} \mathrm{MeHg}$ in the presence or absence of increasing concentrations (1-100 $\mu \mathrm{M}$ ) of diphenyl diselenide (DD; $A$ ); 3'3-ditrifluoromethyldiphenyl diselenide (DFD; $B$ ); $p$-chloro-diphenyl diselenide (CLD; $C$ ), and $p$-methoxy-diphenyl diselenide (MD; $D$ ). Effect of compounds alone on TBARS induction $(E)$. Data are reported as means \pm SD of percent of control for 4-6 separate assays carried out in duplicate. ${ }^{*} \mathrm{P}<0.05$ compared to MeHg alone (ANOVA and Duncan post hoc test). The dashed line indicates the control without $\mathrm{MeHg}(100 \%)$. 
A

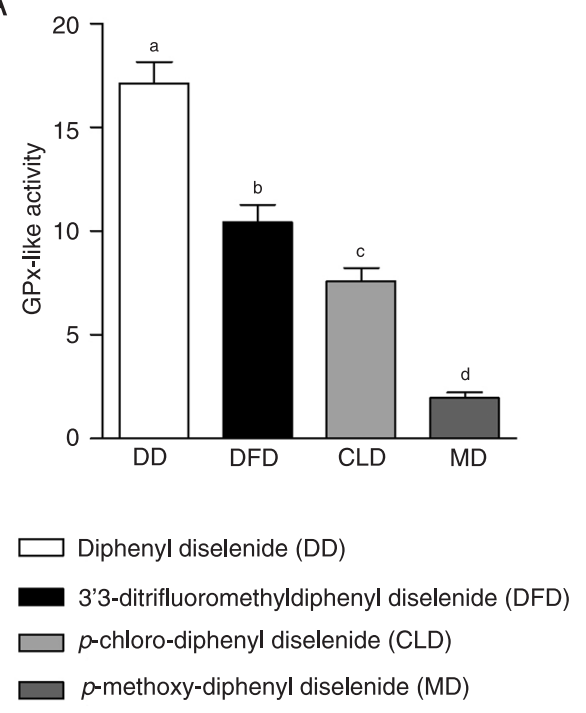

B

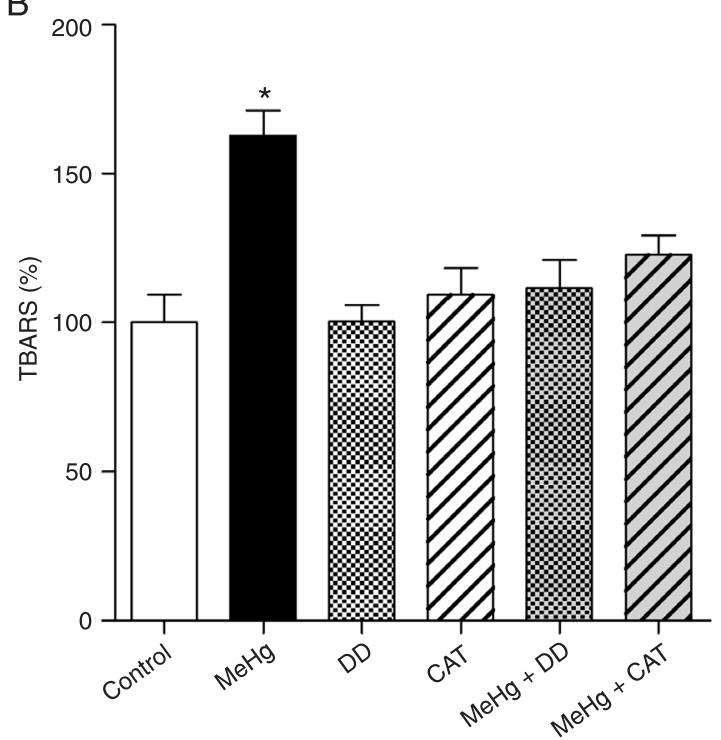

Figure 6. A, Glutathione peroxidase (GPx)-like activity of organodiselenides. A solution of each compound was added to cuvettes and GPx activity was determined as described in the Material and Methods section. Small letters indicate statistical differences between compounds, considering GPx-like activity $(\mathrm{P}<0.05$; ANOVA and Duncan post hoc test). $B$, Effect of DD and catalase (CAT) on MeHg-induced lipid peroxidation (thiobarbituric acid reactive species, TBARS). ${ }^{*} \mathrm{P}<$ 0.05 compared to control and to all other groups tested (ANOVA and Duncan post hoc test).

$\mu \mathrm{M}$. However, DFD and CLD (Figure 5B and C) blocked the increase in lipid peroxidation promoted by $\mathrm{MeHg}$ only at the highest concentration $(100 \mu \mathrm{M})$, while MD did not demonstrate a protective potential against lipid peroxidation induced by $\mathrm{MeHg}$ (Figure 5D). There was no significant TBARS induction by compounds alone (Figure $5 \mathrm{E}$ ).

\section{Glutathione peroxidase-like activity of organoselenium compounds}

In a previous report (24), our group demonstrated that $\mathrm{H}_{2} \mathrm{O}_{2}$ generation represents a relevant event in $\mathrm{MeHg}$ mediated oxidative stress in mouse brain mitochondria. GPx (EC 1.11.1.9) is a main cellular antioxidant responsible for the removal of peroxides in the brain (29). Thus, considering that GPx-like activity of organoselenium compounds is potentially involved in their antioxidant properties, we investigated the in vitro GPx-like activity of each compound. As observed in Figure 6A, DD demonstrated a higher GPx-like activity when compared to the other compounds tested. The order of magnitude for GPx-like activity was DD $>$ DFD > CLD > MD. In parallel experiments, in order to confirm whether the anti-peroxidative activity of DD is linked to its peroxide removal ability, we incubated mouse brain mitochondrial-enriched fractions with $\mathrm{MeHg}$ in the presence or absence of $\mathrm{DD}$ and catalase, an enzyme involved in the clearance of $\mathrm{H}_{2} \mathrm{O}_{2}$. As shown in Figure 6B, MeHg-induced lipid peroxidation was completely reversed by catalase (200 U) as well as $100 \mu \mathrm{M} \mathrm{DD}$, confirming that removal of peroxides is an important mechanism responsible for the protective effects of DD in our study model.

\section{Discussion}

In the present study, we used isolated brain mitochondria as a model to investigate $\mathrm{MeHg}$ toxicity, since this organelle represents a major target for MeHg in cells and plays a pivotal role in the initiation of biochemical cascades that lead to cell death $(30,31)$. The effects of $\mathrm{MeHg}$ on mitochondrial function are associated with loss of the regular organization of the cristae (32) and dissipation of mitochondrial membrane potential $(18,17,33)$.

The acute treatment of mitochondrial-enriched fractions from mouse brain with $\mathrm{MeHg}$ caused a decrease in mitochondrial activity, in agreement with previously reported results for kidney, brain and striatal mitochondrial fractions $(17,24,34)$. This effect occurred in parallel to an increase in lipid peroxidation and GSH depletion. The relationship between ROS formation and mitochondrial damage after $\mathrm{MeHg}$ exposure is not fully understood. ROS can cause oxidative damage to mitochondria, leading to compromised mitochondrial function $(35,36)$. On the other hand, ROS can also be produced by the mitochondria via leakage of electrons from the electron transport chain to molecular $\mathrm{O}_{2}$, forming superoxide anion radicals $\left(\mathrm{O}_{2} \cdot{ }^{-}\right)$. The $\mathrm{O}_{2} \cdot{ }^{-}$is converted to $\mathrm{H}_{2} \mathrm{O}_{2}$ by the mitochondrial enzyme manganese superoxide dismutase (MnSOD) (37). Although this process occurs normally at a low rate in intact mitochondria, $\mathrm{O}_{2}$ production can be dramatically increased if mitochondria 
are challenged by toxicants (38). It was previously demonstrated that treatment with $\mathrm{MeHg}$ causes an increase in $\mathrm{H}_{2} \mathrm{O}_{2}$ generation as well inhibition of GPx activity $(15,16,39)$, which could be responsible in part for the increase in lipid peroxidation observed in our model. We confirmed the participation of $\mathrm{H}_{2} \mathrm{O}_{2}$ formation in $\mathrm{MeHg}$ toxicity when we incubated the brain mitochondria with catalase. This $\mathrm{H}_{2} \mathrm{O}_{2}$ detoxifying enzyme was able to ameliorate the increase in lipid peroxidation promoted by $\mathrm{MeHg}$, which points to an involvement of $\mathrm{H}_{2} \mathrm{O}_{2}$ in the lipid peroxidation promoted by $\mathrm{MeHg}$ and suggests that the GPx-like activity of DD is involved in the antioxidant effect against $\mathrm{MeHg}$.

DD (30 and $100 \mu \mathrm{M})$ protected mouse brain mitochondria against $\mathrm{MeHg}$ toxicity by reversing the $\mathrm{MeHg}$-induced loss of mitochondrial activity/viability. Among the novel organoselenium compounds tested here, only DFD partially reversed the effect of $\mathrm{MeHg}$ on mitochondrial activity at the highest concentration $(100 \mu \mathrm{M})$. The co-treatment with DD completely blocked TBARS production by $\mathrm{MeHg}$. This effect was observed from $10 \mu \mathrm{M}$ up to $100 \mu \mathrm{M}$ of this compound. The novel organodiselenides DFD and CLD were able to reverse the increase in lipid peroxidation promoted by $\mathrm{MeHg}$ only at $100 \mu \mathrm{M}$, emphasizing a higher efficiency of DD as a protective antioxidant, as demonstrated in previous studies (6-8).

GPx mimetic compounds can degrade hydroperoxides, consuming thiol reserves. Such ability confers to these compounds the capacity of protecting cells against oxidative stress conditions (7). The GPx-like activity of DD was significantly higher than the activity of DFD, CLD and $\mathrm{MD}$, an effect possibly related to the higher antioxidant and protective effects of this compound. This result was confirmed by the fact that incubation of samples with catalase, which removes $\mathrm{H}_{2} \mathrm{O}_{2}$, avoided TBARS formation induced by $\mathrm{MeHg}$ exposure. These data suggest that the protective and antioxidant actions of DD are linked to its ability to remove peroxides. $\mathrm{MeHg}$ is known to increase $\mathrm{H}_{2} \mathrm{O}_{2}$ formation by mitochondria $(24,34)$. In this regard, the GPx mimetic activity of DD may represent a promising tool against the cytotoxic effects of this environmental neurotoxin. The lack of protective effect of the organo-

\section{References}

1. Finkel T, Holbrook NJ. Oxidants, oxidative stress and the biology of ageing. Nature 2000; 408: 239-247.

2. Mugesh $G$, Singh $H$. Synthetic organoselenium compounds as antioxidants: glutathione peroxidase activity. Chem Soc Rev 2000; 29: 347-357.

3. Arteel GE, Sies H. The biochemistry of selenium and the glutathione system. Environ Toxicol Pharmacol 2011; 10: 153-158.

4. Paulmier $\mathrm{C}$. Selenium reagents and intermediates in organic synthesis. Oxford: Pergamon Press; 1986.

5. Nogueira CW, Zeni G, Rocha JB. Organoselenium and diselenides DFD, MD and CLD may be related to their lower peroxidase-like activity compared to DD. A recent study from our group has shown the central role of GPx in the toxicity of $\mathrm{MeHg}$ (40). In that study, we showed that $\mathrm{MeHg}$ was able to decrease GPx activity in cell and animal models. In addition, the inhibition of GPx activity with mercaptosuccinic acid increased cell susceptibility to the toxic effects of methylmercury. On this basis, it seems plausible that DD, which showed higher thiol peroxidase activity than the other three substituted diselenides tested here, had the most prominent protective effects against methylmercury-induced oxidative stress and loss of mitochondrial activity in vitro. In addition to the antioxidant properties of selenium compounds, the ability to bind $\mathrm{Hg}$ ions may represent an important mechanism for cytoprotection. In fact, a recent study from our group showed that $\mathrm{DD}$ is able to remove $\mathrm{Hg}$ from tissues (22), reinforcing the therapeutic potential of selenium compounds against $\mathrm{Hg}$ intoxication.

The data reported here reinforce the antioxidant and protective potential of DD when comparing to other substituted organodiselenides. Our findings support the fact that compounds with glutathione peroxidase-like activity are potent blockers of mercurial-induced neurotoxic actions. In addition, our data indicate that depending on the chemical substitutions made on DD, its GPx-like activity may be impaired, which is crucial for the protective capacity of the compound. Considering that oxidative stress has been implicated in $\mathrm{MeHg}$ toxicity and that there are no effective treatments available to counteract the toxic effects of $\mathrm{MeHg}$, the use of DD may represent an important therapeutic approach.

\section{Acknowledgments}

Research supported by a CNPq grant to T. Posser, a FAPERGS grant to J.L. Franco, CNPq grants to D.F. Meinerz and M.T. de Paula (\#140030/2011-5 and \#556081/2010-2, respectively), a FAPERGS-PRONEX grant to J.B.T. Rocha, CNPq and FAPESC grants to M. Farina and A.L. Dafre, and FINEP research grants "Rede Instituto Brasileiro de Neurociência (IBN-Net)". organotellurium compounds: toxicology and pharmacology. Chem Rev 2004; 104: 6255-6285.

6. Farina M, Frizzo ME, Soares FA, Schwalm FD, Dietrich $\mathrm{MO}$, Zeni G, et al. Ebselen protects against methylmercuryinduced inhibition of glutamate uptake by cortical slices from adult mice. Toxicol Lett 2003; 144: 351-357.

7. Posser T, Franco JL, dos Santos DA, Rigon AP, Farina M, Dafre AL, et al. Diphenyl diselenide confers neuroprotection against hydrogen peroxide toxicity in hippocampal slices. Brain Res 2008; 1199: 138-147.

8. Posser T, Moretto MB, Dafre AL, Farina M, da Rocha JB, 
Nogueira CW, et al. Antioxidant effect of diphenyl diselenide against sodium nitroprusside (SNP) induced lipid peroxidation in human platelets and erythrocyte membranes: an in vitro evaluation. Chem Biol Interact 2006; 164: 126-135.

9. Clarkson TW, Magos L, Myers GJ. The toxicology of mercury - current exposures and clinical manifestations. $N$ Engl J Med 2003; 349: 1731-1737.

10. Malm O. Gold mining as a source of mercury exposure in the Brazilian Amazon. Environ Res 1998; 77: 73-78.

11. Myers GJ, Davidson PW, Strain JJ. Nutrient and methyl mercury exposure from consuming fish. J Nutr 2007; 137: 2805-2808.

12. Aschner M, Syversen T, Souza DO, Rocha JB, Farina M. Involvement of glutamate and reactive oxygen species in methylmercury neurotoxicity. Braz J Med Biol Res 2007; 40: 285-291.

13. Ou YC, White CC, Krejsa CM, Ponce RA, Kavanagh TJ, Faustman EM. The role of intracellular glutathione in methylmercury-induced toxicity in embryonic neuronal cells. Neurotoxicology 1999; 20: 793-804.

14. Shanker G, Syversen T, Aschner JL, Aschner M. Modulatory effect of glutathione status and antioxidants on methylmercury-induced free radical formation in primary cultures of cerebral astrocytes. Brain Res Mol Brain Res 2005; 137: 11-22.

15. Farina M, Cereser V, Portela LV, Mendez A, Porciúncula LO, Fornaguera J, et al. Methylmercury increases S100B content in rat cerebrospinal fluid. Environ Toxicol Pharmacol 2005; 19: 249-253.

16. Mori N, Yasutake A, Hirayama K. Comparative study of activities in reactive oxygen species production/defense system in mitochondria of rat brain and liver, and their susceptibility to methylmercury toxicity. Arch Toxicol 2007; 81: 769-776.

17. Dreiem A, Gertz CC, Seegal RF. The effects of methylmercury on mitochondrial function and reactive oxygen species formation in rat striatal synaptosomes are age-dependent. Toxicol Sci 2005; 87: 156-162.

18. Araragi $S$, Kondoh M, Kawase M, Saito S, Higashimoto $M$, Sato M. Mercuric chloride induces apoptosis via a mitochondrial-dependent pathway in human leukemia cells. Toxicology 2003; 184: 1-9.

19. Shenker BJ, Guo TL, Insung O, Shapiro IM. Induction of apoptosis in human T-cells by methyl mercury: temporal relationship between mitochondrial dysfunction and loss of reductive reserve. Toxicol Appl Pharmacol 1999; 157: 23-35.

20. Tchounwou PB, Ayensu WK, Ninashvili N, Sutton D. Environmental exposure to mercury and its toxicopathologic implications for public health. Environ Toxicol 2003; 18: 149-175.

21. Moretto MB, Funchal C, Santos AQ, Gottfried C, Boff B, Zeni $\mathrm{G}$, et al. Ebselen protects glutamate uptake inhibition caused by methyl mercury but does not by $\mathrm{Hg}^{2+}$. Toxicology 2005; 214: 57-66.

22. de Freitas AS, Funck VR, Rotta MS, Bohrer D, Morschbacher V, Puntel RL, et al. Diphenyl diselenide, a simple organoselenium compound, decreases methylmercuryinduced cerebral, hepatic and renal oxidative stress and mercury deposition in adult mice. Brain Res Bull 2009; 79: 77-84.

23. Roos DH, Puntel RL, Santos MM, Souza DO, Farina M, No- gueira CW, et al. Guanosine and synthetic organoselenium compounds modulate methylmercury-induced oxidative stress in rat brain cortical slices: involvement of oxidative stress and glutamatergic system. Toxicol In Vitro 2009; 23: 302-307.

24. Franco JL, Braga HC, Stringari J, Missau FC, Posser T, Mendes BG, et al. Mercurial-induced hydrogen peroxide generation in mouse brain mitochondria: protective effects of quercetin. Chem Res Toxicol 2007; 20: 1919-1926.

25. Ellman GL. Tissue sulfhydryl groups. Arch Biochem Biophys 1959; 82: 70-77.

26. Ohkawa H, Ohishi N, Yagi K. Assay for lipid peroxides in animal tissues by thiobarbituric acid reaction. Anal Biochem 1979; 95: 351-358.

27. Bradford MM. A rapid and sensitive method for the quantitation of microgram quantities of protein utilizing the principle of protein-dye binding. Anal Biochem 1976; 72: 248-254.

28. Wendel A. Glutathione peroxidase. Methods Enzymol 1981; 77: 325-333.

29. Dringen R, Pawlowski PG, Hirrlinger J. Peroxide detoxification by brain cells. J Neurosci Res 2005; 79: 157-165.

30. Aschner M, Syversen T. Methylmercury: recent advances in the understanding of its neurotoxicity. Ther Drug Monit 2005; 27: 278-283.

31. Atchison WD, Hare MF. Mechanisms of methylmercuryinduced neurotoxicity. FASEB J 1994; 8: 622-629.

32. O'Kusky J. Methylmercury poisoning of the developing nervous system: morphological changes in neuronal mitochondria. Acta Neuropathol 1983; 61: 116-122.

33. Stavrovskaya IG, Kristal BS. The powerhouse takes control of the cell: is the mitochondrial permeability transition a viable therapeutic target against neuronal dysfunction and death? Free Radic Biol Med 2005; 38: 687-697.

34. Lund BO, Miller DM, Woods JS. Studies on Hg(II)-induced $\mathrm{H}_{2} \mathrm{O}_{2}$ formation and oxidative stress in vivo and in vitro in rat kidney mitochondria. Biochem Pharmacol 1993; 45: 20172024.

35. Galindo MF, Jordan J, Gonzalez-Garcia C, Cena V. Reactive oxygen species induce swelling and cytochrome $c$ release but not transmembrane depolarization in isolated rat brain mitochondria. Br J Pharmacol 2003; 139: 797-804.

36. Radi R, Cassina A, Hodara R, Quijano C, Castro L. Peroxynitrite reactions and formation in mitochondria. Free Radic Biol Med 2002; 33: 1451-1464.

37. Shanker G, Aschner JL, Syversen T, Aschner M. Free radical formation in cerebral cortical astrocytes in culture induced by methylmercury. Brain Res Mol Brain Res 2004; 128: 4857.

38. Halliwell B, Gutteridge JMC. Free radicals in biology and medicine. New York: Oxford University Press; 1999.

39. Carvalho MC, Franco JL, Ghizoni H, Kobus K, Nazari EM, Rocha JB, et al. Effects of 2,3-dimercapto-1-propanesulfonic acid (DMPS) on methylmercury-induced locomotor deficits and cerebellar toxicity in mice. Toxicology 2007; 239: 195203.

40. Franco JL, Posser T, Dunkley PR, Dickson PW, Mattos JJ, Martins $\mathrm{R}$, et al. Methylmercury neurotoxicity is associated with inhibition of the antioxidant enzyme glutathione peroxidase. Free Radic Biol Med 2009; 47: 449-457. 